\title{
AVALIAÇÃO DA EFICIÊNCIA ENERGÉTICA E DA SUSTENTABILIDADE EM EDIFICAÇÕES COM USO DE FERRAMENTAS BIM
}

\author{
Carolina Issa $^{(1)}$, Emerson Ferreira ${ }^{(2)}$, Juliana Borges ${ }^{(3)}$ \\ (1) Universidade Federal da Bahia, Salvador \\ (2) Universidade Federal da Bahia, Salvador \\ (3) Senai Cimatec, Salvador
}

\begin{abstract}
Resumo
A indústria da Construção Civil representa um grande impacto ambiental, com o consumo excessivo de energia não renovável ao longo de todo o ciclo de vida da edificação. Surge então a necessidade de construir de forma mais sustentável, sendo necessário a melhoria dos processos de projeto, construção e operação, a fim de utilizar os recursos apropriados minimizando os impactos ambientais. O principal objetivo deste estudo foi avaliar as potencialidades dos softwares de simulação computacional para análise da eficiência energética e sustentabilidade dos projetos ao longo do ciclo de vida, com o uso do BIM. A metodologia inclui uma revisão sistemática da literatura e análise das funcionalidades de softwares para verificação da eficiência energética integrados ao BIM, com relação às variáveis de posicionamento do edifício, sombreamento, invólucro, uso e materiais constituintes. Os resultados alcançados indicaram a importância da avaliação energética dos edifícios com a utilização do BIM, as principais vantagens e limitações no uso dos softwares e a influência das variáveis para um melhor desempenho e sustentabilidade das edificações.
\end{abstract}

\section{Introdução}

A preocupação com o uso racional de energia está cada vez mais em evidência, principalmente na indústria da construção civil. Devido ao aumento de emissão de $\mathrm{CO}_{2}$, conforme a Agência Internacional de Energia [1], o setor da AECO (Arquitetura, Engenharia, Construção e Operação), é responsável por mais de um terço do consumo final global de energia e por quase $40 \%$ do total de emissões diretas e indiretas de $\mathrm{CO}_{2}$. O setor de Construção Civil é um dos sete setores dominantes que contribuem muito para as emissões globais de gases de efeito estufa (GEE) [2].

Torna-se fundamental investir em pesquisas que mitiguem estes impactos, com o uso da tecnologia BIM e simulações computacionais. Estudo realizado sobre o impacto ambiental e emissão de $\mathrm{CO}_{2}$ gerado pelo setor da Construção Civil, desde da fase de concepção, até a de uso e operação do edifício, citou que várias são as iniciativas para minimizar os impactos ambientais promovidos pelas edificações residenciais, e identificou que a etapa operacional é a 
mais relevante pelo significativo consumo de energia, chegando a contribuições superiores a $80 \%$ em várias categorias de impacto [3].

A necessidade de responder ao desafio do aumento da população mundial é, contudo, um caminho vicioso para um problema maior da sustentabilidade global. Ao passo que aumenta-se as infraestruturas, amplia-se o número de emissões de poluentes e a já conhecida reputação de um setor altamente tóxico para o bem-estar do meio ambiente [4].

Considerando a problemática do cenário mundial, perante os impactos ambientais causados pela AECO, principalmente na fase de uso e operação do edifício, se torna imprescindível utilizar métodos de simulação virtuais da eficiência energética nos projetos com a ferramenta BIM, principalmente na fase de concepção de projeto. Os objetivos básicos da sustentabilidade devem ser estabelecidos já no início do projeto, o que resulta em metas significativas que permitem avaliar as opções e o progresso alcançado [5].

A avaliação de desempenho energético de edificações é uma tarefa complexa que envolve grande quantidade de variáveis interdependentes e conceitos multidisciplinares. Com o uso do computador foi possível desenvolver modelos computacionais para representar o comportamento térmico, luminoso e energético de edificações, através da simulação de diferentes cenários, permitindo a análise de alternativas distintas de eficiência energética quando a edificação está em fase de projeto ou após a construção [6].

Este panorama reforça a importância de investigar o processo de adoção do BIM com foco na sustentabilidade da edificação. O objetivo principal do estudo foi relatar as potencialidades da utilização de ferramentas BIM, nos softwares Revit 2019 e Archicad 21, assim como as complexidades para inserção dos dados, trazendo à tona aspectos simples projetuais que podem ser mitigados com a criação de um modelo de energia.

\section{Revisão bibliográfica}

\subsection{Sustentabilidade das edificações}

A sustentabilidade das edificações está intimamente ligada ao desempenho térmico do projeto, visando aproveitamento passivo dos recursos naturais, otimização nas escolhas tecnológicas dos subsistemas construtivos e materiais de construção. Aumenta a cada dia a responsabilidade da sociedade atual e principalmente dos profissionais da área AECO, de vincular os novos empreendimentos ao processo sustentável desde a fase conceitual do projeto arquitetônico.

A construção sustentável, é um sistema construtivo que promove intervenções ao meio ambiente de forma a atender as necessidades de uso, produção e consumo humano, sem esgotar os recursos naturais, preservando-os para as gerações atuais e futuras [7].

A eficiência energética das edificações é importante para otimizar os níveis de consumo e consequentemente reduzir o impacto ambiental de geração de energia [8].

As origens do movimento das edificações sustentáveis não advem de um único evento, desvem de episódios cumulativos cujas raizes remotam aos primordios da humanidade, onde ancestrais do homem eram muito apegados ao meio ambiente, já que sua sobrevivencia dependia dele [5]. Portanto, tinham que adaptar ao clima local e aos recursos naturais existentes o seu abrigo. Estudiosos identificaram em suas pesquisas que independentemente da vertente tecnológica, as soluções de projeto para o conforto ambiental e a eficiência energética relacionam os mesmos conhecimentos, com os recursos locais e com a tecnologia apropriada [9]. 
Os diálogos mais recentes acerca da temática iniciaram no início dos anos 90, com a formação do Comitê de Meio Ambiente do Instituto Americano de Arquitetos (AIA) (COTE) e formação do Green Building Council dos EUA (USGBC) [10]. A construção verde do início dos anos 90 poderia ter contido apenas determinados materiais com algum conteúdo reciclado, porém, um edifício hodierno que está se aproximando da sustentabilidade considerará todo o ciclo de vida do produto.

\subsection{Green BIM e simulações computacionais}

Atualmente vivi-se uma mudança drástica no contexto da Construção Civil como um todo, principalmente no que diz respeito aos avanços das tecnologias, através do impulso cada vez mais amadurecido e difundido das plataformas BIM (Building Modeling Information) na indústria da Arquitetura, Engenharia, Construção e Operação (AECO).

A implementação do BIM nos processos de projeto, construção e de obra apresenta um elevado potencial de otimização do planejamento e execução de projetos multidisciplinares, gerando impactos positivos em sua qualidade de projeto. Resultando num aumento da produtividade da equipe de trabalho, redução de gastos totais em construções, minimização de erros em documentos, identificação de informações de longevidade do edifício e seu ciclo de vida, dentre outras infinitas possibilidades. Ao contrário dos métodos tradicionais, que os resultados podem ser alcançados com mais lentidão, podendo até fragmentar o processo de produção, isolando os profissionais de diferentes disciplinas e ocasionando uma falta de coordenação entre as equipes participantes [11].

No âmbito da sustentabilidade, pode-se destacar o processo BIM como um grande estímulo para a Avaliação do Ciclo de Vida (ACV) de uma construção, onde durante o processo projetual podem ser identificados impactos ambientais negativos a serem solucionados e/ou minimizados antes mesmo da sua execução e o aproveitamento racional dos recursos da natureza através do conceito de qualidade ambiental [12].

Existe uma gama de possibilidades e de softwares que permitem realizar analises voltadas para sustentabilidade e eficiência energética, como: IES $\langle V E\rangle$ (Integrated Enviromental Solutions); Ecotect; Green Building Studio (Revit); Equest; Energy Plus; Daysim; Radiance; Climate Consultant; WUFI-ORNL/IBP; Excel; EcoDesigner STAR (Archicad). Neste artigo, vamos aprofundar mais sobre as ferramentas BIM de avaliação energética dos softwares Archicad 21 e Revit (Green Building Studio) [10].

\section{Metodologia}

O presente trabalho adotou como método de pesquisa o estudo de caso, sendo avaliadas as potencialidades dos softwares Archicad e Revit voltados para análise energética para edifícios de habitação de interesse social. O modelo parametrizado utilizado foi de um edifício do Programa Minha Casa Minha Vida, localizado em Camaçari, Bahia, Brasil. No primeiro momento, foi realizada uma análise do modelo, sucessivamente pré-configurações de dados para Análise Energética para realização das simulações. Ápos a extração dos relatórios das simulações, foram identificadas as potencialidades e fraquezas dos softwares escolhidos.

O estudo de caso é um método capaz de analisar uma situação fenômeno, no seu próprio meio natural, devido ao fato de poder-lhe aplicar variadas metodologias para a coleta de dados com o intuito de obter diversificadas informações [13]. No caso em apreço, diversos instrumentos 
de coleta de informação, como: estudos aprofundado e simulações computacionais nos softwares Green Build Studio (Revit) e EcoDesign STAR (ArchiCAD 21).

Para o desenvolvimento da pesquisa, a fim de comparar os resultados alcançados com a realidade, foi realizada uma pesquisa qualitativa de campo, com alguns moradores do empreendimento para avaliação do grau de satisfação dos usuários e para rebater os valores da simulação com a realidade. As pesquisas qualitativas são muito adotadas quando o procedimento técnico utilizado é o estudo de caso. A pesquisa qualitativa possibilita uma relação mais íntima entre o sujeito e o mundo real, como uma ligação direta da objetividade e da subjetividade do homem que jamais poderia ser codificada em números, possibilitando deste modo, uma visualização única de situações [14].

Como fontes de evidencia de informação foram utilizados livros, revistas periódicas, artigos, dissertações, teses, sites oficiais, entre outros.

\section{Resultados}

A partir dos softwares BIM escolhidos para realizar os estudos de análises energéticas Archicad (EcoDesigner STAR - Energy Evaluation); e Revit (Green Building Studio), foram descritos resultados a respeito de sua utilidade, potencialidades e limitações nas simulações de modelo de energia.

\subsection{Archicad (EcoDesigner STAR - Energy Evaluation)}

O Archicad é um software BIM voltado para arquitetura, desenvolvido pela companhia Graphisoft ${ }^{\circledR}$, que tem a ferramenta de análise energética o "EcoDesigner STAR" (Graphisoft ${ }^{\circledR}$, 2020). Para utilização do simulador o projetista deve pré-configurar com informações parametrizadas ao modelo BIM, para obter os relatórios de eficiência energética.

$\mathrm{O}$ modelo BIM pode ser utilizado em todas as disciplinas relacionadas ao edifício, ou seja, também para o modelo BEM (Building Energy Model, Modelo de Energia). O BEM pode ser utilizado como ferramenta interativa, a fim de desenvolver um feedback entre o projeto e eficiência energética do edifício [15].

Para formatação do modelo BEM, foram configuradas algumas etapas no Ecodesigner; quais sejam: definir a localização manualmente (latitude e longitude); definir os perfis de operação, dados climáticos, sistemas do edifício, fatores de fontes de energia e custo de energia; identificar e agrupar as zonas em "blocos térmicos" por similaridade de perfil operacional e térmico; organizar e definir os materiais construtivos de acordo com o que será executado, preenchendo suas informações de propriedades físicas, térmicas e condutivas do material; e, definir orientação solar do projeto (inclinação do norte).

Após cumpridas as etapas, é possível gerar um relatório sobre o modelo BEM, com identificação simultânea dos elementos a serem analisados, tanto dos construtivos gerais, quanto de elementos especificos, por exemplo: alvenarias, portas e janelas.

Existem algumas formas de extrair informações do modelo, uma delas é selecionar o objeto que deseja fazer análise e fazer a leitura dos seus dados de análise energética individualmente. (Exemplo: Ao selecionar uma janela, é possível abrir a análise solar da mesma com um diagrama solar da porcentagem de área envidraçada exposta diretamente a luz do sol em cada hora do dia, durante todos os dias do ano (Figura 1)). É possível também comparar análises de 
objetos diferentes, visto que cada caso é uma situação específica a ser analisada e, possivelmente, encontrada uma nova solução utilizando artifícios de proteção solar.

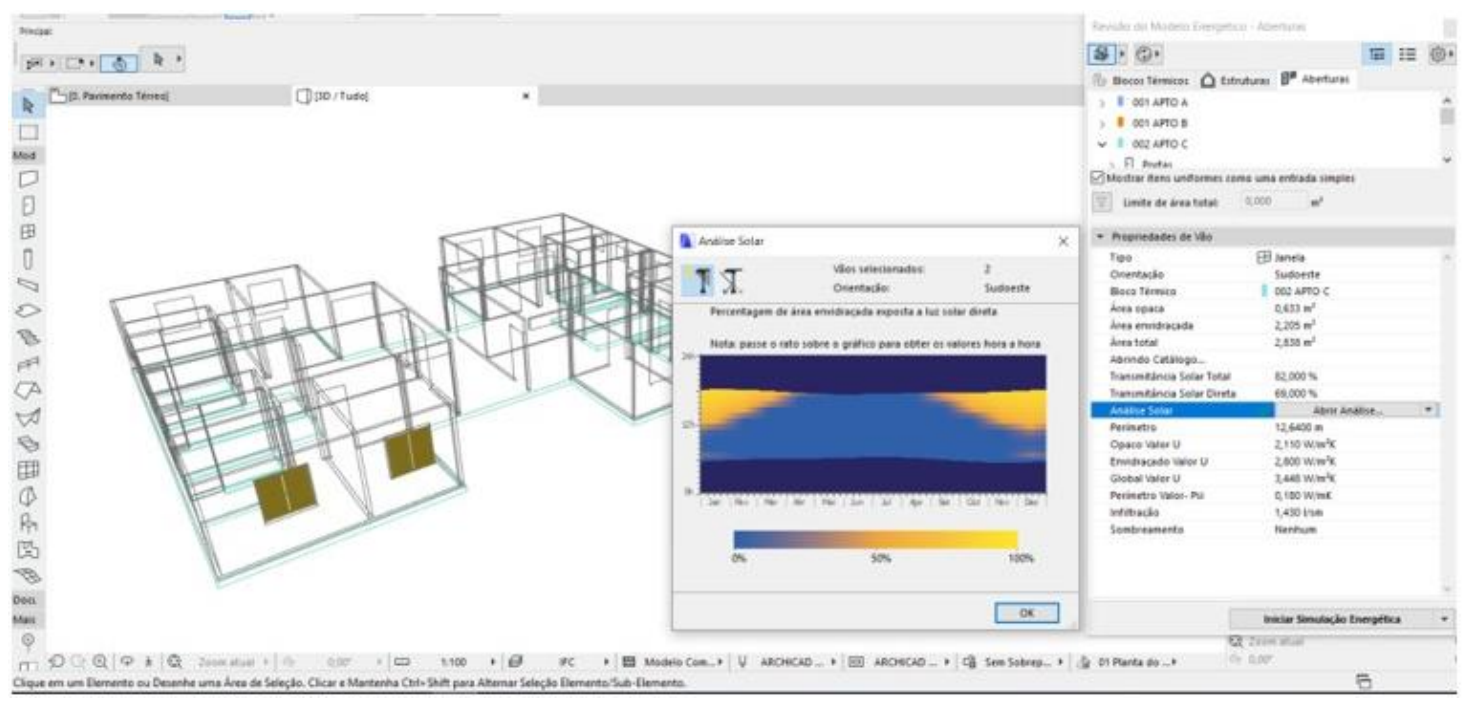

Figura 1: Análise solar do elemento janela, com informações de incidência solar.

Outra extração de informação do modelo BEM é o Workflow ("Fluxo de Trabalho"), onde é gerado uma tabela completa com diversos dados analisados a partir das configurações acima. Após a verificação dos dados, existe a possibilidade de exportar o documento em arquivo de Construção Base (.bas), gbXML, PHPP e VIP-Energy.

$\mathrm{O}$ relatório pode ser emitido na fase de estudo preliminar do edifício para, juntamente com as decisões dos projetistas, fazer a tomada de decisões e, caso necessário, realizar mudanças. Abaixo serão ilustradas (Figuras 2 e 3 ) algumas informações que o relatório oferece, a partir das pré-configurações realizadas pelo usuário.

Dentre as informações emitidas pelo relatório estão: Informações/Valores chave do projeto; Consumo de Energia por Fontes; Consumo de Energia por Objetos; Balanço Energético; Resumo do Sistema Renovável do Edifício; Impacto Ambiental; Mensagens de Aconselhamentos; Perfil da Temperatura Diária; Consumo de Energias e Economias; Linha de Base do Desempenho e Custos de Energia; Dados de HVAC/AVAC; Avaliação de Desempenho.

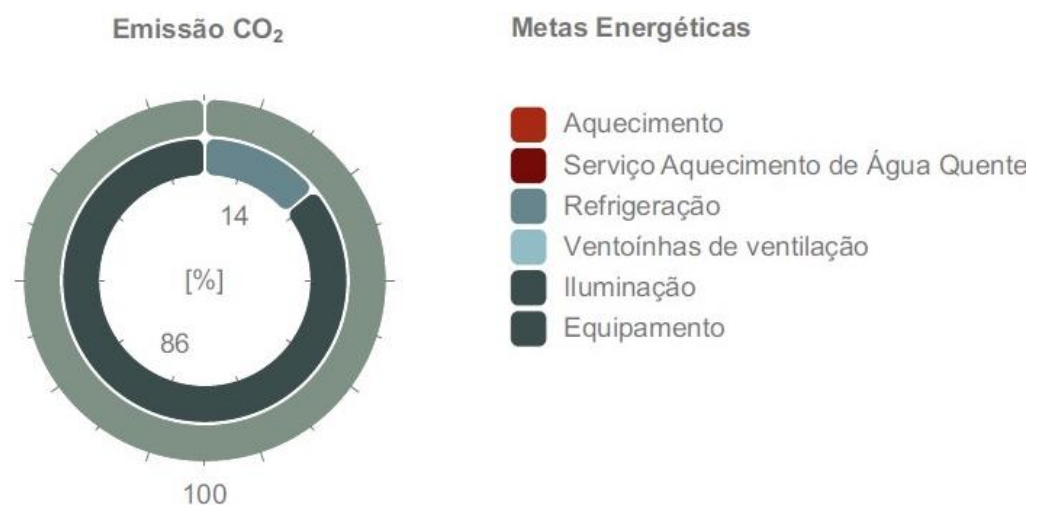

Figura 2: Informação gráfica em porcentagem (\%) dos sistemais emitem $\mathrm{CO}_{2}$ no edifício. 


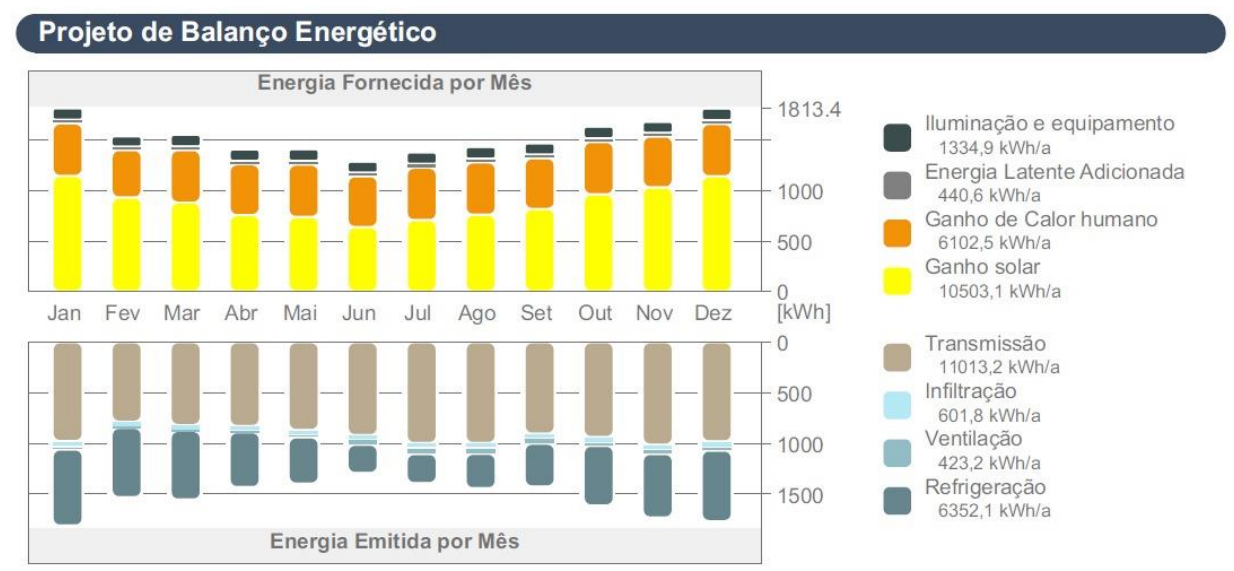

Figura 3: Projeto de Balanço Energético.

\subsection{Revit (Green Building Studio)}

Ao contrário do Archicad, o Green Building Studio é um software da Autodesk® que permite a criação de simulação energética na nuvem, podendo ser utilizado do projeto conceitual ao detalhado [16]. Pode ser criado um modelo de energia (BEM), obtendo resultados para analise da orientação solar, involocro, cobertura e vedações verticais externas e internas.

No comando "Configurações Avançadas de Energia" (Figura 4), são definidos no próprio Revit, os seguintes atributos: Percentual de destino da vidraça, altura de destino do parapeito, pode-se marcar se a vidraça está sombreada, definir o tipo da construção, assim como a tabela de operações da construção, que define o horário de operação do edificio, por exempo, 12/7 (12 horas por 7 dias da semana). Além das propriedades térmicas do material que é definida conforme padrões pré estabelecidos pelo sistema.
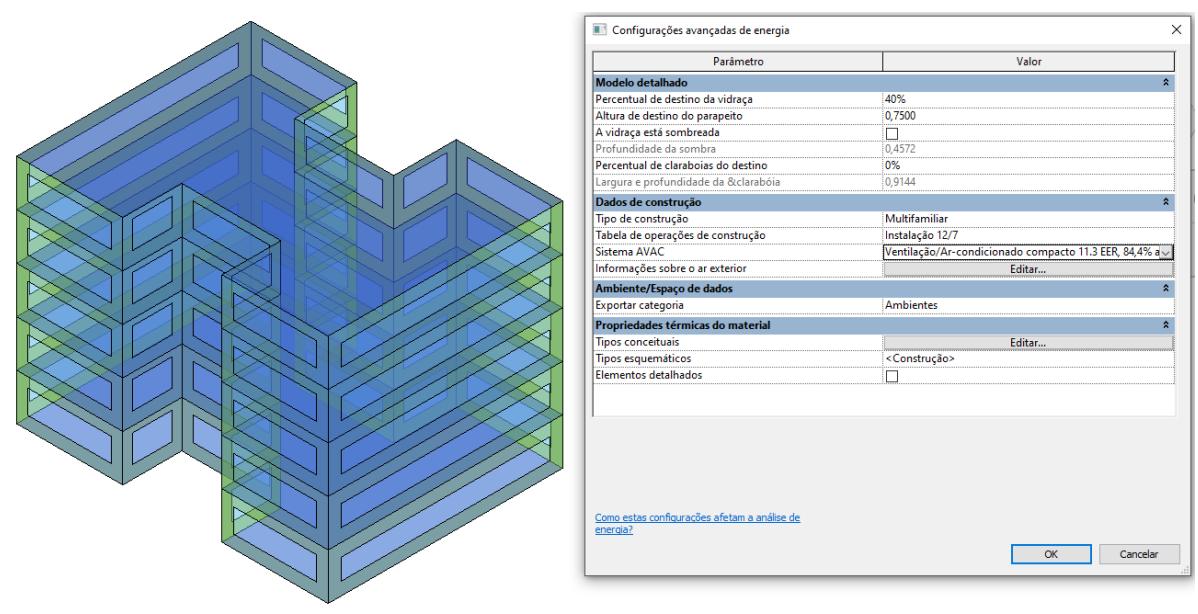

Figura 4: Modelo de Massa Conceitual com janela de configurações avançadas de energia.

Para criação do modelo analítico de energia e para atingir maior precisão dos resultados, é possível definir com facilidade, através do "Serviço de Mapeamento pela Internet" a estação metereológica vinculada ao projeto (Figura 5), neste estudo foi utilizada a estação número "861326",situada próxima a Rua Francisco de Assis, Camaçari, Bahia. Atribuindo assim dados fundamentais das temperaturas anuais de "Bulbo seco" e "Bulbo molhado". 


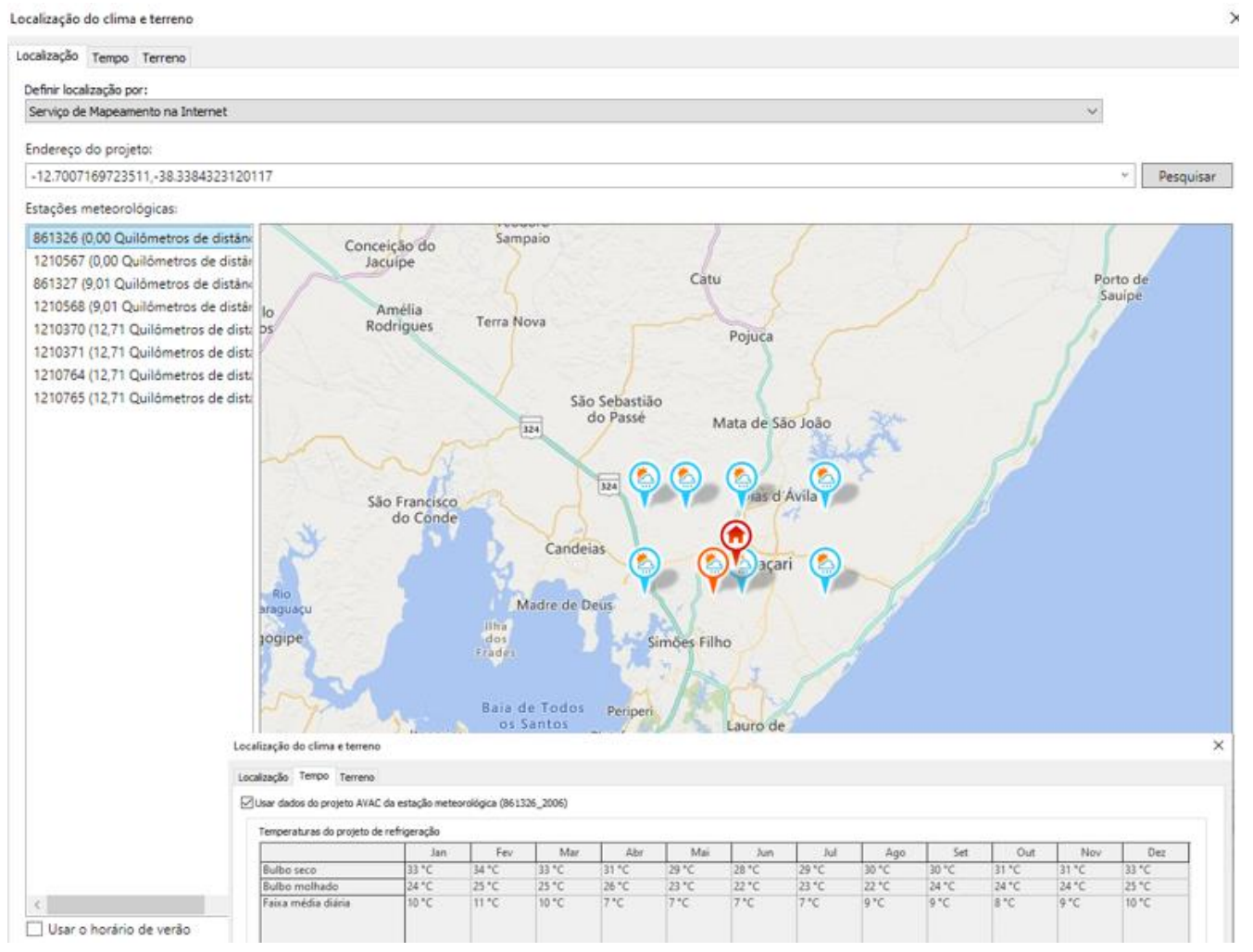

Figura 5: Inserção da estação meteorológicas.

É possivel utilizar três fluxos de trabalhos para realização da simulação de energia: Elementos de massa conceitual que, através do estudo volumétrico do edificio, pode-se definir com rapidez a opção do volume com a menor carga térmica e maior eficiência energética, estabelecendo nesta etapa a orientação mais adequada para obtenção dos resultados básicos com atributos especificos do software (Figura 6). É possivel fazer estudos comparativos de orientação de construção, além de outros resultados estudos de máscaras de sombra, enfatizando o ganho energetico; propriedades dos vidros, das paredes e da cobertura, infiltração do edificio, com respectivos consumo energetico categorizado em gráficos anuais.

O segundo fluxo seria Elementos de espaços/ salas e no terceiro são utilizados os Elementos de construção, constituido por todo modelo detalhado e parametrizado com informações técnicas das camadas e subsistemas, com as "propriedades analíticas" dos materiais contituintes do sistema (Coeficiência de Transfêrencia de Calor (U), Resistência Térmica (R), Massa Térmica, Absorção e Rugosidade). Nesta última opção tem-se resultados analíticos, com definições mais precisas da eficiência dos sistemas, constituindo a sua integridade para o projeto executivo.

Neste caso, foi realizado um estudo de massa conceitual, porém não foi possível realizar a análise térmica com os elementos de construção devido operação do sistema. A troca de dados entre representações de edificações e simulações tem sido um grande desafio, pois trata-se de um processo de tradução trabalhoso e sujeito a erros [17]. Porém, o esquema gbXML foi desenvolvido especialmente para facilitar a transferencia de informações da edificação armazenadas em modelos de simulações, o que permite atualmente a interoperabilidade integrada entre os modelos de construção. 


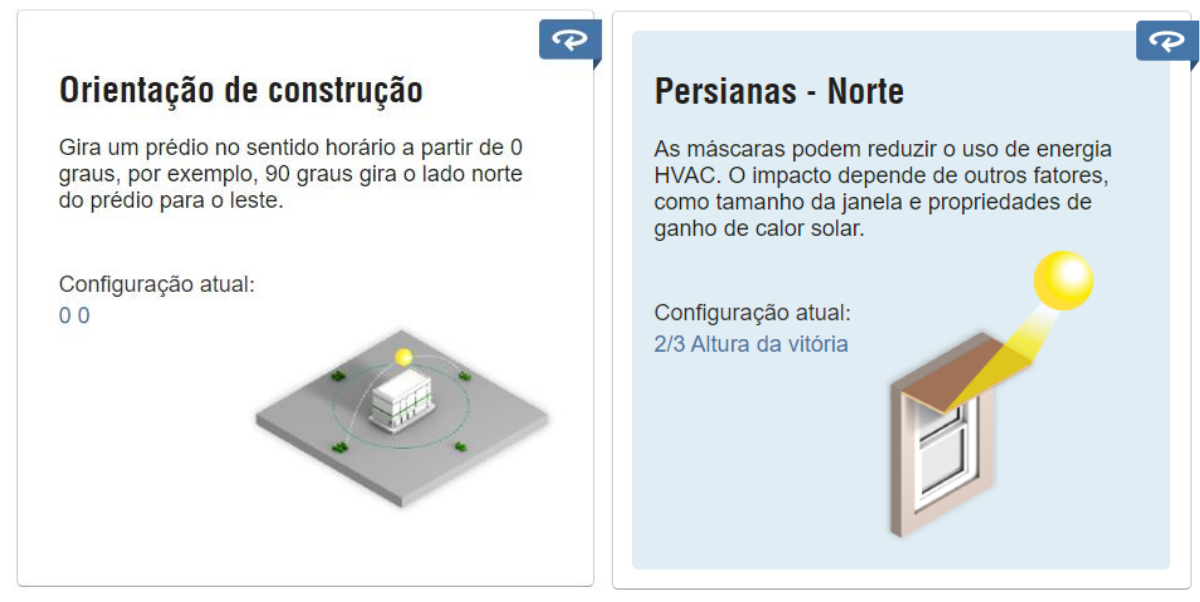

Figura 6: Resultado gerado na Nuvem.

\section{Discussão}

A partir dos resultados obtidos e explorados dos softwares acima citados, pode-se listar algumas potencialidades que os tornam eficientes no momento das tomadas de decisões projetuais. A Tabela 1 abaixo serve como parâmetro que norteia a escolha destes softwares para a análise de eficiência energética em modelos BIM.

Tabela 1: Potencialidades e Fraquezas dos Softwares estudados

$\begin{array}{cc}\text { Archicad } 21 & \text { Revit } \\ \text { EcoDesigner STAR } & \text { Green Building Studio }\end{array}$

\section{POTENCIALIDADES}

Rapidez na emissão de relatórios com o modelo BEM já configurado.

Interface dinâmica e intuitiva.

Disponível offline.

Exportação para diferentes extensões: (gbXML, Arquivo de Construção Base (.bas), PHPP e VIP-Energy)

Emissão de relatório com gráficos ilustrativos informando dados energéticos, valores de consumo e custos.

Informações de emissão de $\mathrm{CO} 2$ pelo edifício.

Ferramenta de Análise Energética faz parte do próprio software.
Rapidez na emissão de relatórios com o modelo BEM já configurado.

Interface dinâmica e intuitiva.

Disponível na nuvem online.

Exportação para diferentes extensões: (gbXML, IFC, FBX, CAD E DWF)

Possibilidade de Estudo de Massas Conceituais e Modelos de Construção

Inserção da estação metereólogica mais próxima ao edificio.

Emissão de relatório ilustrativo, com custos energéticos por categorias. 


\section{FRAQUEZAS}

Alta demanda de tempo e atenção na organização para o modelo BEM.

Complexidade de uso em nível médio.

Necessidade de realizar ajustes manuais no modelo BIM, diminuindo a produtividade.

Não é possível analisar massas conceituais.

Os dados metereológicos devem ser preenchido manualmente, não obtendo a estação meteorologica on line.
Alta demanda de tempo e atenção na organização para o modelo BEM.

Complexidade de uso em nível médio.

Necessidade de realizar ajustes manuais no modelo BIM, diminuindo a produtividade.

Falha da criação do modelo de energia com elementos de construção.

Erros na interface entre modelo BEM e resultados na nuvem.

A pesquisa em campo, constatou que as simulações indicaram resultados próximos a realidade, atingindo um grau de eficiência energética satisfatória para um prédio de habitação de interesse social.

Os usuários entrevistados, em sua totalidade relataram satisfação com o conforto térmico e lumínico. A implantação dos edifícios, com eixo rotacionado $-45^{\circ}$ em relação ao norte, minimizou a incidência solar direta e garantiu a permeabilidade da ventilação dominante local (NE e SE) e iluminação natural nos ambientes. Sendo assim, o micro clima local foi valorizado e e os resultados do relatório do Archicad para o pavimento tipo indicaram: temperatura média anual entre $23,71^{\circ} \mathrm{C}$ e $26,79^{\circ} \mathrm{C}$, Consumo de Energia - 44,14 kWh/m², Emissão $\mathrm{CO} 2$ - 2,12 $\mathrm{kg} / \mathrm{m}^{2} \mathrm{a}$ (kilograma por $\mathrm{m}^{2}$ anual).

\section{Conclusão}

As características estudadas dos softwares de simulação energética, permitiram visualizar as potencialidades e fraquezas, bem como as principais diferenças entre eles. Entende-se como uma importante ferramenta de auxílio para o desenvolvimento do projeto, desde a concepção inicial. Os resultados permitiram analisar a qualidade energética do edifício e conforto dos usuários, tendo sido observado diferentes níveis de dificuldade para a realização das simulações. Sugere-se pesquisa posterior sobre a interoperabilidade entre os modelos BIM e BEM.

\section{Referências}

[1] AIE Agência Internacional de Energia. Titulo do post "Edifícios Uma fonte enorme de potencial de eficiência inexplorado. Acessado em 03 de janeiro de 2020, https://www.iea.org/topics/buildings.

[2] C. Mao, Q. Shen, L. Shen, L. Tang, Comparative study of greenhouse gas emissions between off-site prefabricationandconventionalconstructionmethods: Two Case studies of residential projects. Elsevier B.V. vol. 32, pp. 1-13, July 2013. 
[3] P.P.A.E. Evangelista, "Desempenho Ambiental na Construção Civil: Parâmetros para aplicação da avaliação do ciclo de vida em edificações residenciais brasileiras," Tese de Doutoramento, Universidade Federal da Bahia, Salvador, BA, 2017.

[4] B.F.B. Martins, "Utilização de BIM e métodos de sustentabilidade em elementos da construção," Dissertação de Mestrado, Universidade de Porto, Portugal, 2018.

[5] M.Keeler, B. Burke, Fundamentos de Projeto de Edificações Sustentáveis. Editora Bookman, Porto Alegre, 2010, ISBN 9788577807338.

[6] E. L. Didone, F. O. R. Pereira, "Simulação computacional integrada para a consideração da luz natural na avaliação do desempenho energético de edificações" Ambiente Construído (2010), Porto Alegre, v. 10, n. 4, p. 139-154, out./dez. 2010. ISSN 16788621.

[7] C.C.C. Cunha, and A.C.S. Siqueira, Aspectos sustentáveis da construção de uma subestação no interior da Bahia. ConGeA, IV Congresso Brasileiro de Gestão Ambiental, IBEAS - Instituto Brasileiro de Estudos Ambientais, Salvador/BA - 25 a 28/11/2013.

[8] L. K. S. Oliveira, R. M. Rêgo, M. N. M. A.Rutuoso, S. S. F. B. Rodrigues, "Simulação computacional da eficiência energética para uma arquitetura sustentável," HOLOS, Ano 32, Vol. 4, 2016, DOI: 10.15628/holos.2016.3981.

[9] J.C.S. Gonçalves, and D.H.S. Duarte, “Arquitetura sustentável: uma integração entre ambiente, projeto e tecnologia em experiências de pesquisa, prática e Ensino." Ambiente Construído (2006), Porto Alegre, v. 6, n. 4, p. 51-81 out./dez. 2006. ISSN 1415-8876.

[10]E. Krygiel, B. Nies, Green BIM: Sucessful Sustainable Design with Building Information Modeling. Editora Wiley Publishing, Inc., Canadá, 2016, ISBN 9780470239605.

[11] R.D. Miranda, and L. Salvi, "Análise da tecnologia Bim no contexto da indústria da construção civil brasileira." Revista Científica Multidisciplinar, Núcleo do Conhecimento. Ano 04, Ed. 05, Vol. 07, pp. 79-98, 2019.

[12] B. V. Barreto, J. L. G. Sanches, T. L. G. Almeida, S. E. C. Ribeiro, "O Bim no Cenário de Arquitetura e Construção Civil Brasileiro." Revista Construindo. Minas gerais, v. 08, n.2,jul./dez. 2016.

[13]R. YIN, "Estudo de caso: planejamento e métodos". Porto Alegre: Bookman, 2010, ISBN 85-7307-852-9

[14]A. C. GIL, "Como elaborar projetos de pesquisa". São Paulo: Atlas, 2008, ISBN: 97885- 224-3169-4

[15] T.Reeves, S. Olbina, R. Issa, "Validation of building energy modeling tools: Ecotect, Green Building Studio ${ }^{\mathrm{TM}}$ and IES ${ }^{\mathrm{TM}}$ ". In: Winter Simulation Conference (2012) Berlin, Proceedings, WSC, 2012. p. 582-593.

[16] Autodesk, "Building Performance Analysis Raised to the Power of the Cloud," Autodesk Revit homepage, Acessado em 14 de Janeiro 2020, https://gbs.autodesk.com/GBS/ Anuncio.

[17]G. R. Queiróz, “Análise da interoperabilidade entre os programas computacionais Autodesk Revit e Energyplus para simulação térmica de edificações,", ," Dissertação de Mestrado, Universidade Federal de Santa Maria, Santa Maria, RS, 2016. 